\title{
NÂNG CAO CHẤT LƯợNG HỌC TẬP NHÓM THÔNG QUA VIẸC TĂNG CƯờnG HỌC TẬP CÁ NHÂN VÀ VAI TRÒ CỦA GIẢNG VIÊN TRONG DẠY HỌC TÍCH CỰC

\author{
Trần Lê Thăng Đồng ${ }^{(*)}$, Đàm Minh Tùng ${ }^{(*)}$, Nguyễn Chiến Thắng ${ }^{(* *)}$
}

(*) Thac sĩ. Đại học Duy Tân. Email: tranlethangdong@duytan.edu.vn.

(**) Tiến sĩ. Đại học Duy Tân. Email: nguyenchienthang@duytan.edu.vn.

DOI: $10.37550 /$ tdmu.CFR/2021.01.143

\section{Tóm tắt}

Vận dụng và cải tiến các hình thức học và dạy học theo huớng tích cưc luôn là nhũ̃ng hoạt động thiết yếu trong việc cải thiện chất luợng đào tạo theo CDIO. Trong bài viết này, chúng tôi tập trung phân tích các ưu và khuyết điểm của việc học tập cá nhân cũng nhu học tập nhóm trong trưòng Đại học dựa trên một loạt các quan sát, phỏng vấn và thảo luận nhóm, qua đó đề xuất một số phưong pháp để nâng cao hiệu quả học tập của sinh viên trong các môn học và làm đồ án. Mặc dù tất cả chúng ta đều nhận thức rõ ràng việc hoc tập nhóm đem lại nhũng hiệu quả rõ rệt, nhung kết quả là luôn có sụ khác biệt trong quá trình hoàn thành nhiệm vu giữa các sinh viên có trình độ kiến thức và tư duy không đồng đều nhau. Do đó, vấn đề trọng tâm được đặt ra là phát triển các kỹ năng giao tiếp cá nhân trong việc xây dưng nhóm. Việc tập trung vào thảo luận nhóm được theo dõi thông qua việc lấy ý kiến của tù̀ng sinh viên cuối cùng cũng đã cho thấy nhũng phản hồi tích cực mặt dù vẫn còn một số sinh viên cho rằng phwơng pháp mới đòi hỏi họ phải dành nhiều thời gian hơn so với cách hoc bình thuờng, Tuy nhiên quan trọng hơn, tì̀ việc lấy ý kiến này, chúng tôi cũng thu nhận được thêm một số phương pháp học tập mới cũng như cách thức tự hoàn thiện bản thân tù chính các sinh viên của chúng tôi.

Từ khoá: Dạy học tích cục, CDIO, mô hình FSNPA, Learning Pyramid, học tập cá nhân, họ tập nhóm, Pull, Balance, Push

\section{1. Đặt vấn đề}

Học tập nhóm là quá trình chia sẽ và bổ sung kiến thức cho nhau giữa các thành viên trong một nhóm cùng làm việc vì các mục tiêu chung [1]. Theo đó, luôn có sự ràng buộc và phụ thuộc lẫn nhau về vai trò cũng như nhiệm vụ của mỗi thành viên trong nhóm, do đó, sự thống nhất về mục tiêu, việc phân công phân nhiệm và ủy thác công việc một cách công bằng và hợp lý của nhóm trưởng là một trong số những yếu tố chủ chốt quyết định sự thành công của nhóm [5]. Ngoài ra sự kết hợp năng lực học tập của các thành viên trong nhiều lĩnh vực cũng là một yếu tố góp phần vào sự thành công này. Chính vì vậy, học tập nhóm đã và đang ngày càng 
được áp dụng rộng rãi trong các trường đại học ở hầu hết các môn học.

Tuy nhiên, bên cạnh đó học tập nhóm cũng bị cản trở bởi nhiều vấn đề nảy sinh trong suốt quá trình phát triển của nhóm. Theo mô hình FSNPA (Forming - Storming - Norming Performing - Adjourning) của Tuckman, quá trình này có thể bị phá vỡ ở các giai đoạn khác nhau nếu các thành viên trong nhóm không thể tìm thấy sự đồng thuận và thống nhất trong các hoạt động [7]. Tại Đại học Duy Tân (DTU), học tập nhóm được xem là tâm điểm của quá trình triển khai $\mathrm{CDIO}$, tuy nhiên, rất nhiều lần chúng tôi quan sát và thấy rằng sinh viên các ngành kỹ thuật dường như không nhận ra được những lợi ích của việc học nhóm vì nhiều sự cố khác nhau xảy ra trong quá trình phát triển nhóm. Nguyên nhân chủ yếu của điều này xuất phát từ những vấn đề liên quan tới giao tiếp và sự khác biệt về tỷ lệ hoàn thành công việc và chất lượng của sản phẩm do sự khác nhau về nền tảng kiến thức và kỹ năng của từng sinh viên. Để cải thiện việc học và làm việc nhóm hiệu quả, chúng tôi đã khuyến khích các Khoa, Tổ bộ môn cùng tìm những phương pháp tốt hơn cho công tác triển khai CDIO. Trong bài viết này, dựa trên một loạt các quan sát, phỏng vấn và tập trung vào thảo luận nhóm, chúng tôi sẽ đề xuất một số biện pháp nhằm tăng tường vài trò của giảng viên và học tập cá nhân để nâng cao chất lượng học tập nhóm trong các đồ án CDIO.

\section{Những nguyên nhân dẫn đến thất bại trong việc xây dựng nhóm và học tập nhóm}

Chúng tôi tái khẳng định lại những lợi ích của việc học nhóm là không hề dư thừa nhằm sàng lọc kỹ hơn và tìm ra những điểm bất cập gây trở ngại cho quá trình nhận thức những lợi ích này của sinh viên. Như hình 1 , tháp học tập thể hiện tỉ lệ phần trăm khả năng tiếp thu kiến thức tương ứng với các hoạt động học tập của sinh viên [4]. Có thể dễ dàng nhận thấy mức độ tiếp thu kiến thức có sự khác nhau giữa các hoạt động học tập, trong đó tỷ lệ duy trì kiến thức cao nhất tập trung ở các hoạt động thảo luận nhóm, thực hành và dạy lại cho người khác. Tất cả những hoạt động này đều được thực hiện theo nhóm, điều này thể hiện tầm quan trọng và lợi ích rõ ràng của việc học nhóm. Vậy đâu là nguyên nhân khiến học tập nhóm gặp thất bại?

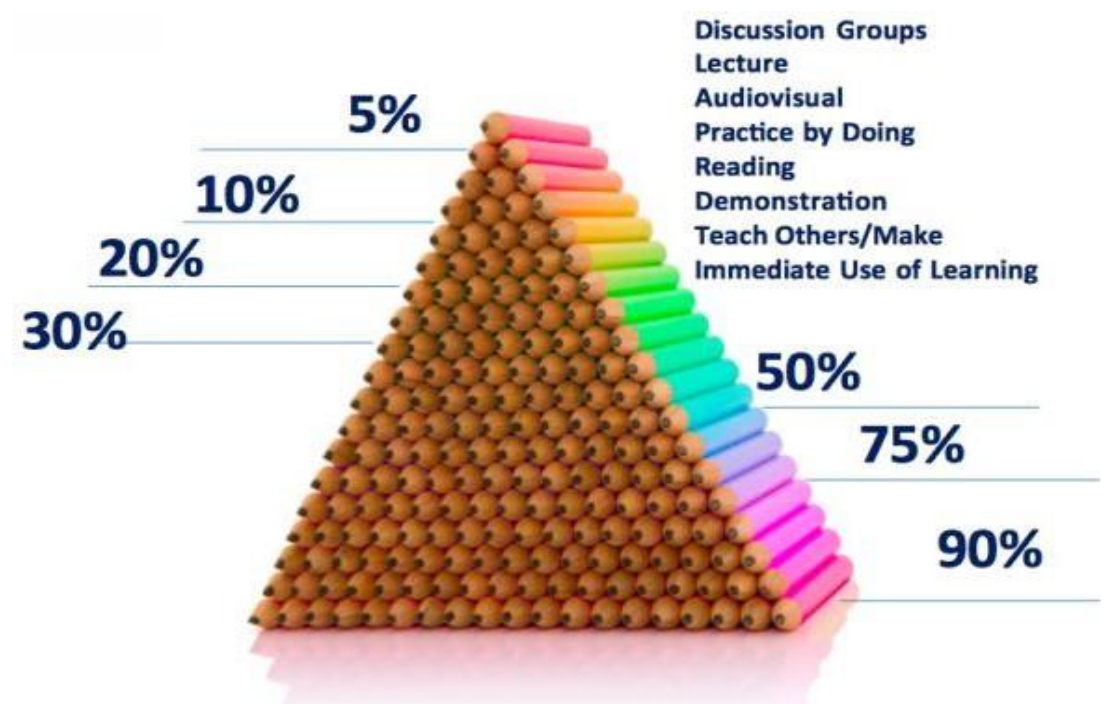


Hinh 1. Tháp họ tập - National Training Laboratories, Bethel, Maine

Để trả lời cho câu hỏi trên, chúng tôi liệt kê một số những yêu cầu cần phải đạt được để việc học và làm việc nhóm thành công (những yêu cầu này cũng đã được xác nhận trong qua trình quan sát của chúng tôi tại DTU):

- Sự đồng thuận cao ở tất cả các thành viên trong nhóm là điều cần thiết cho sự thành công của nhóm [1]. Sẽ không có sự đồng thuận này nếu như các thành viên trong nhóm không có cùng mục tiêu và tầm nhìn khi xây dựng nhóm.

- Trong nhóm, mọi thành viên đều phải dành sự ưu tiên cao nhất cho việc hoàn thành mục tiêu chung [1]. Nếu không thực hiện được điều này thì các thành viên sẽ không nhìn thấy được tầm quan trọng của việc hoàn thành những mục tiêu đã đề ra.

- Việc áp dụng phương pháp quản lý phù hợp cũng góp phần và sự thành công của nhóm [5]. Nếu không tìm ra phương pháp quản lý tốt thì các thành viên trong nhóm sẽ không có sự kết nối khi làm việc và hiểu ý nhau khi giao tiếp.

- Môi trường học và làm việc một cách dân chủ cũng là một yếu tố cần thiết cho sự thành công của nhóm, nó giúp cho các thành viên chia sẽ ý tưởng và nâng cao tinh thần đồng đội [2]. Sẽ không thể xây dựng một môi trường như vậy nếu tất cả mọi mục tiêu và công việc chỉ được đề xuất và thực hiện bởi một thành viên nào đó hoặc trong nhóm không có sự thống nhất về ý kiến dẫn tới sự mâu thuẫn trong nội bộ.

- Cơ hội được cùng làm việc và học tập cần phải được chia sẽ công bằng cho tất cả các thành viên trong nhóm [1]. Nếu chỉ tập trung hoàn thành mục tiêu mà bỏ qua việc giúp đỡ, hỗ trợ và trao cơ hội cùng thực hiện nhiệm vụ cho các thành viên có năng lực yếu trong nhóm thì việc học tập nhóm vẫn bị đánh giá là chưa thành công.

\section{Những bất cập trong việc học tập nhóm tại Trường Đại học Duy Tân}

Với một loạt những nguyên nhân khiến việc học tập nhóm gặp thất bại như đã nêu ở trên, chúng tôi nhận thấy hầy hết các sự cố đều tập trung ở vấn đề giao tiếp. Để xác định chính xác đâu mới thật sự là mấu chốt của vấn đề về giao tiếp đang diễn ra trong các lớp học đồ án CDIO tại DTU, chúng tôi đã xây dựng một số câu hỏi phóng vấn được sắp xếp theo một thứ tự nhất định để có thể thu nhận được nhiều thông tin hơn từ phía sinh viên về những sự cố thường gặp trong học nhóm và làm việc nhóm. Ngoài ra một số câu hỏi về vai trò của giảng viên cũng được thêm vào quá trình phỏng vấn để đánh giá tính hiệu quả của giảng viên hướng dẫn trong việc theo dõi và quản lý các hoạt động làm việc nhóm của sinh viên.

Bảng 1. Câu hỏi phỏng vấn dành cho sinh viên

\begin{tabular}{|c|l|}
\hline Câu hỏi & \multicolumn{1}{c|}{ Nội dung } \\
\hline 1 & Cho biết ý kiến tổng quát của bạn về việc học nhóm? \\
\hline 2 & Bạn có cho rằng học tập nhóm thật sự quan trọng và cần thiết? \\
\hline 3 & Nhóm của bạn thường có bao nhiêu thành viên? Số lượng thành viên nam và thành viên nữ? \\
\hline 4 & Theo bạn, điều gì gây trở ngại nhất đến quá trình học tập nhóm? \\
\hline 5 & $\begin{array}{l}\text { Bạn có thường xảy ra mâu thuẫn với nhóm trưởng không? Nhóm trưởng của bạn có cách quản } \\
\text { lý và điều hành nhóm tốt không? }\end{array}$ \\
\hline
\end{tabular}




\begin{tabular}{|c|l|}
\hline 6 & $\begin{array}{l}\text { Là thành viên của một nhóm, bạn hãy tự đánh giá mức độ tham gia của mình? Bạn có thấy } \\
\text { mình là thành viên nhàn rồ trong nhóm không? }\end{array}$ \\
\hline 7 & Bạn thường tranh luận về vấn đề nào trong nhóm? Giải thích? \\
\hline 8 & $\begin{array}{l}\text { Bạn và các thành viên trong nhóm có cùng các mục tiêu và tầm nhìn trong suốt quá trình thực } \\
\text { hiện đồ án hay không? }\end{array}$ \\
\hline 9 & $\begin{array}{l}\text { Giảng viên của bạn có tạo điều kiện và giúp đỡ nhóm bạn không? Bạn có hài lòng với sự giúp } \\
\text { đỡ đó không? }\end{array}$ \\
\hline 10 & Theo bạn điều gì là thiếu sót lớn nhất của giảng viên gây ảnh hưởng đến quá trình học nhóm? \\
\hline
\end{tabular}

Việc phỏng vấn được thực hiện tại 04 lớp học thuộc các chuyên ngành Xây dựng, Điện tử viễn thông, Môi trường, Công nghệ phần mềm và hệ thống thông tin. Số lượng sinh viên tham gia phỏng vấn trong từng lớp học dựa trên số lượng sinh viên nhiều hay ít của từng lớp. Trong tổng số 100 lượt sinh viên được phỏng vấn thì có $65 \%$ là nam và $35 \%$ là nữ. Kết quả phỏng vấn thu được, ngoài một số ý kiến khác biệt thì đa số sinh viên đều đưa ra những đáp án đáng buồn khiến cho những bất cập của việc học nhóm trở nên rõ ràng hơn và cho phép chúng tôi đưa ra một số nhận định, đánh giá như sau:

- Nhìn nhận về tầm quan trọng và sự hiệu quả của học tập nhóm thường chia thành hai thái cực. Trong khi một số sinh viên rất hài lòng với môi trường học tập nhóm tại DTU thì một số khác lại hoàn toàn không đủ hài lòng để nhận ra bất kỳ sự quan trọng nào của việc học nhóm.

- Những rào cản lớn gây trở ngại cho việc học tập nhóm tại DTU gồm có:

oCác thành viên trong nhóm thể hiện cái tôi quá lớn, họ chỉ muốn bảo vệ ý kiến của mình trong các cuộc họp của nhóm, khiến cho việc xác định mục tiêu chung của nhóm bị chậm trễ và có nguy cơ không thể thực hiện được.

o Trong một nhóm luôn có sự phân hoá về mức độ tham gia của các thành viên, có sinh viên thì rất năng nổ và nhiệt tình trong mọi hoạt động, nhưng một số khác lại không làm gì cả.

○Những thành viên có học lực giỏi thường có xu hướng áp đặc ý kiến của họ lên các thành viên khác trong nhóm.

- Tương quan số lượng nam sinh và nữ sinh trong các lớp học ở DTU thường không đồng đều. Cụ thể, số lượng nam sinh thường chiếm tỷ lệ cao hơn so với số lượng nữ sinh, vì vậy trong hầu hết các tình huống ý kiến của các thành viên ở nhóm giới tính có số lượng ít sẽ không được xem trọng và họ ít được tham gia quyết định các vấn đề quan trọng của nhóm.

- Có nhiều ý kiến cho biết, thông thường nhóm trưởng được bầu chọn vì họ là người có học lực tốt nhất trong nhóm, tuy nhiên hầu hết các nhóm trưởng này lại không có kinh nghiệm quản lý nhóm tốt như học lực của họ.

- Hầu hết sinh viên đều không cho rằng mình là người nhàn rỗi trong nhóm ngược lại họ phàn nàn rằng mình không thể bắt kịp các thành viên khác và trở nên thụ động trong việc học nhóm.

- Hầu hết sinh viên đều đồng ý rằng giáo viên hướng dẫn tại DTU đã tạo nhiều điều kiện để giúp họ cải thiện việc học nhóm, tuy nhiên họ cũng cho rằng còn rất nhiều khía 
cạnh mà giảng viên cần cải thiện để có thể giúp đỡ họ nhiều hơn.

- Ý kiến than phiền về giảng viên chủ yếu tập trung ở hai vấn đề là một số giảng viên đôi lúc quá trông chờ vào kết quả và chất lượng của đồ án dẫn đến đôi khi họ bỏ qua việc dành thời gian cho việc học tập nhóm của sinh viên, một vấn đề khác là giảng viên thường dành nhiều ưu ái cho những sinh viên có năng lực học tập tốt và nổi bật trong nhóm và bỏ qua các sinh viên khác.

Phía trên là những nhận định chung nhất bên cạnh rất nhiều những ý kiến khác than phiền về những bất cập trong học tập nhóm mà chúng tôi nhận được từ nhiều phía. Chính những điều này thôi thúc chúng tôi phải nỗ lực tìm ra những phương cách tối ưu nhất để giảm thiểu các bất cập đó mà kết quả cuối cùng vẫn là làm sao để đảm bảo việc triển khai các môn học theo CDIO được thuận lợi và có chất lượng mà học tập nhóm là một trong số những hoạt động khá thường xuyên và có mặt ở hầu hết các môn học.

\section{Mô hình FSNPA cho việc phát triển nhóm và ý nghĩa của mô hình này đối với hoạt động dạy học tại DTU}

Như đã nói, việc nêu ra thực tế như trên không phải để làm nản lòng những người đang cổ vũ cho công cuộc triển khai CDIO trong trường học, không phải để làm nản chí những giảng viên năng nổ đang rất cố gắng để truyền đạt tri thức cho sinh viên, mà để cùng nhau nhận diện những giải pháp căn cơ hơn nhằm giúp cho quá trình triển khai CDIO nói chung và các môn học có hoạt động học tập nhóm nói riêng ngày càng chất lượng hơn. Những phản hồi từ các cuộc phỏng vấn đã cho những cái nhìn sâu vào những vấn đề mà chúng tôi cần phải cải thiện và phương cách thực hiện như thế nào để nâng cao chất lượng của việc học nhóm tại DTU bao gồm: 1) Vấn đề giao tiếp giữa các thành viên trong nhóm; 2) Học tập cá nhân và sự tham gia vào hoạt động nhóm của mỗi thành viên trong lớp; 3 ) Vai trò hướng dẫn của giảng viên trong các hoạt động của nhóm.

Bên cạnh việc chúng ta có thể hiểu vì sao cần phải cải thiện kỹ năng giao tiếp của sinh viên và vai trò hướng dẫn của giảng viên, lý do chúng tôi muốn bàn đến vấn đề học tập cá nhân và sự tham gia vào quá trình học nhóm của mỗi sinh viên bởi vì thực tế họ dành quá nhiều thời giờ để tham gia nhóm một cách hiệu quả trong khi đó lại quên mất việc đảm bảo chất lượng học tập cá nhân của chính mình, một vấn đề mà lẽ ra họ cần phải quan tâm và phải được xem trọng trong các hoạt động nhóm [5]. Ngoài ra, không phải lúc nào tất cả các thành viên trong nhóm cũng được chia sẽ đồng đều cơ hội được thể hiện mình trong các hoạt động của nhóm hay của lớp. Đây cũng có thể là nguyên nhân tại sao một số sinh viên rất hài lòng trong khi một số khác không hài lòng với việc học nhóm tại DTU.

Trước khi bàn tới giải pháp cụ thể cho việc cải thiện chất lượng của học tập cá nhân và học tập nhóm, cần xác định được các loại vấn đề mà sinh viên thường gặp và những vấn đề đó thường xuất hiện ở những giai đoạn nào của quá trình xây dựng nhóm để chúng ta tập trung giải quyết những vấn đề này một cách triệt để và có hiệu quả. Có rất nhiều mô hình thể hiện cho quá trình xây dựng và phát triển một nhóm, trong đó mô hình FSNPA của Bruce Tuckman ở hình 2 là một bức tranh tổng thể mô tả tương đối đầy đủ về những giai đoạn phát triển nhóm là mô hình đang được xem xét và chú ý nhiều nhất tại DTU. 


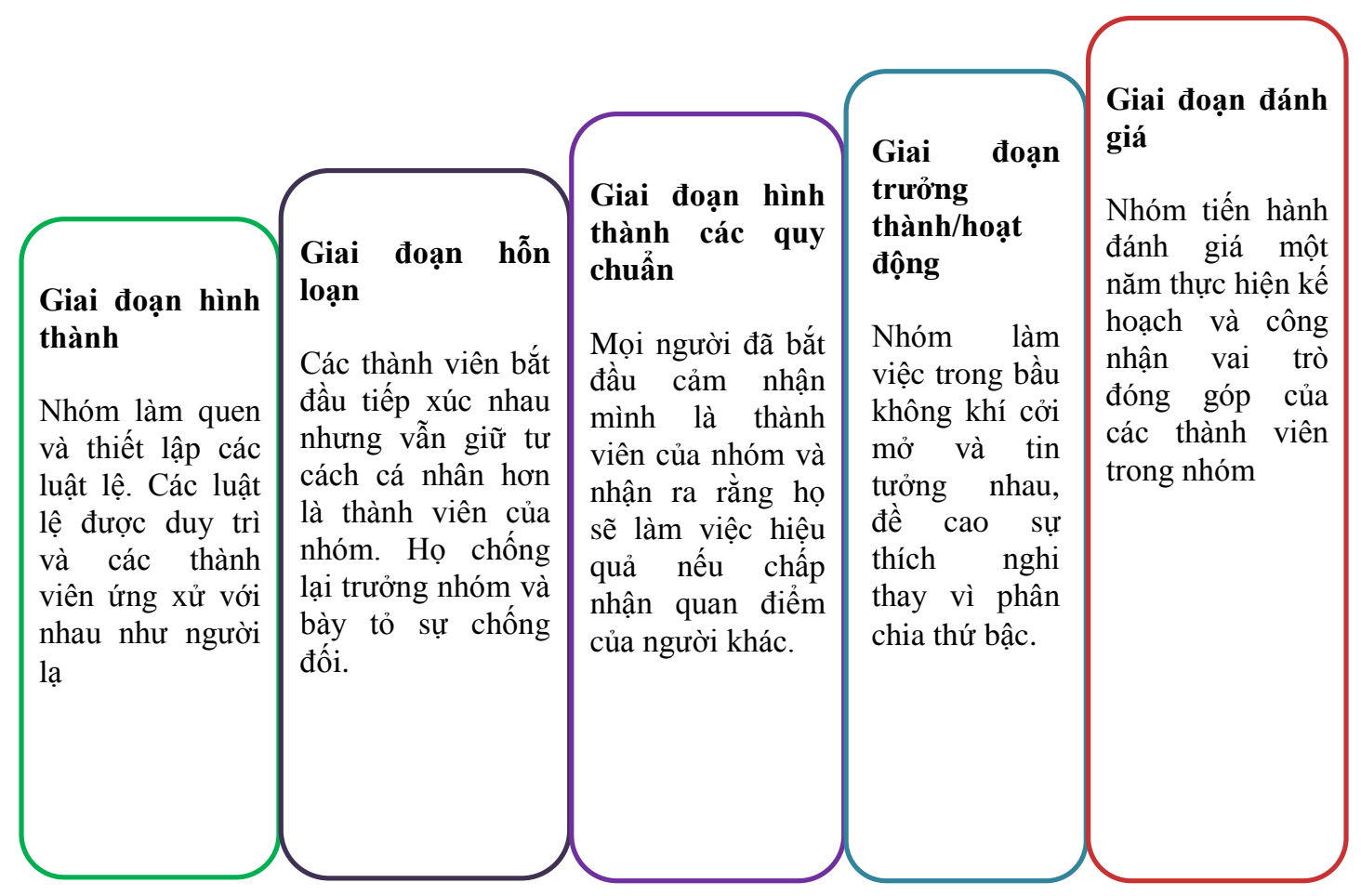

Hình 2. Mô hình FSNPA của Bruce Tuckman

Theo Bruce Tuckman, kể từ khi hình thành đến khi kết thúc, sự phát triển của một nhóm có thể chia thành năm giai đoạn [1]. Giai đoạn hình thành (Forming); Giai đoạn bão tố hay hỗn loạn (Storming); Giai đoạn ổn định hay hình thành các quy chuẩn (Norming); Giai đoạn trưởng thành hay hoạt động (Performing) và cuối cùng là Giai đoạn kết thúc (Adjourning). Trong năm giai đoạn này thì hai giai đoạn $\mathrm{F}-\mathrm{S}$ là rất quan trọng quyết định đến sự phát triển thành công của một nhóm và giảng viên cần phải thể hiện nhiều hơn vai trò của mình ở những giai đoạn này. Đối với các giai đoạn còn lại N-P-A là lúc hầu hết khoản thời gian đều tập trung ở người học, họ sẽ thể hiện vai trò của mình để hoàn thành mục tiêu. Dựa trên đặt trưng của các giai đoạn này, chúng tôi cũng chia các giải pháp của mình thành ba nhóm giải pháp chính là nhóm chiến thuật Pull, nhóm chiến thuật Balance và nhóm chiến thuật Push. Qua đó, có thể thấy rằng mô hình FSNPA có ý nghĩa rất lớn trong việc đem lại cái nhìn tổng quan tương đối chính xác về sự phát triển của nhóm và từ đó chúng tôi có thể bám sát từng giai đoạn và đề xuất giải pháp tháo gỡ những vấn đề còn tồn tại của học tập nhóm một cách có hiệu quả.

\section{Giải pháp tăng cường học tập cá nhân và vai trò của giảng viên thông qua nhóm giải pháp P-B-P}

Nhóm giải pháp $\mathrm{P}-\mathrm{B}-\mathrm{P}$ là kết quả được hình thành từ quá trình thảo luận và đúc kết kinh nghiệm dạy học của một nhóm các giảng viên của Khoa Điện - Điện tử và Khoa Xây dựng. P-B-P là viết tắt của cụm từ Pull-Balance-Push, nhóm giải pháp bao gồm một loạt 
các chiến thuật tập trung vào việc cải thiện kỹ năng giao tiếp của sinh viên, tăng cường học tập và tham gia các hoạt động nhóm của cá nhân và vai trò của giảng viên trong việc tăng cường hỗ trợ các hoạt động nhóm. Các chiến thuật thuộc các nhóm Pull (Lôi kéo), Balance (Cân bằng) và Push (Thúc đẩy) sẽ được áp dụng ở các giai đoạn Forming và Storming của mô hình FSNPA.

\subsection{Nhóm chiến thuật pull}

Nhóm chiến thuật này mang tính lôi kéo, dẫn dắt các mối quan hệ trong nhóm theo chiều hướng tích cực, được thực hiện ở giai đoạn Forming (gia đoạn hình thành) là giai đoạn các thành viên trong nhóm bước đầu tìm hiểu và làm quen nhưng vẫn còn thụ động. Ngay tại thời điểm này giảng viên cần phải tiếp cận, tạo điều kiện và kéo các sinh viên xích lại gần nhau hơn bằng những việc làm thật cụ thể có thể kể tới gồm có:

- Phần lớn giảng viên sẽ giới thiệu ngay về bản thân của mình trước sinh viên. Với mỗi giảng viên, dựa trên kinh nghiệm và kỹ năng của mình sẽ tìm cách tạo nên cho mình một hình ảnh đầy thiện cảm và thân thiện đối với sinh viên, từ đó tạo dựng niềm tin trong sinh viên nhằm tạo điều kiện thuận lợi cho quá trình giao tiếp giữa người dạy và người học sau này. Bên cạnh đó, giảng viên cần phải nói thêm về các đồ án CDIO họ đã hướng dẫn trước đó, điều này sẽ đem lại cho sinh viên một sự hiểu biết tốt về những lợi ích mà giảng viên sẽ đem lại cho họ, và sẽ tốt hơn nữa nếu đưa các tài liệu về các đồ án CDIO trước đó lên diễn đàn sinh viên để sinh viên có thể tham khảo và thảo luận với giảng viên về những đồ án này.

- Dành thời gian cho các sinh viên tự giới thiệu về bản thân. Đây là cách nhanh nhất để mỗi thành viên trong nhóm có được thông tin cá nhân của các thành viên còn lại. Điều này giúp giảng viên có thể nhận diện được những sinh viên có tính cách trầm lặng hoặc quá mức nổi trội để từ đó có những phương pháp can thiệp nhằm tạo sự cân bằng trong nhóm. Mặc dù việc này đôi lúc sẽ tiêu tốn khá nhiều thời lượng của lớp học, tuy nhiên nó sẽ góp phần giúp sinh viên có thể tự xác định được những điểm mạnh, yếu của các thành viên trong nhóm, từ đó sẽ định hình trong việc phân công nhiệm vụ trong nhóm sau này.

- Giảng viên không nên đưa ra yêu cầu quá nhiều trong đồ án và luôn thúc ép sinh viên phải dành toàn bộ thời lượng của lớp học để dành cho việc làm đồ án và học tập. Cần phải dành một khoảng thời gian cho các hoạt động khác bằng cách gợi mở thêm một số nội dung về xã hội để sinh viên đưa ra cách nhìn nhận của mình qua đó bộc lộ nhiều hơn cách suy nghĩ, cá tính của họ, đưa thêm nhiều trò chơi nhóm vận dụng các phương pháp Roleplaying, Think-Pair-Share... để sinh viên có thể giao tiếp, tương tác với nhau nhằm tăng cường mối quan hệ tốt đẹp trong nhóm [3].

- Vào thời điểm giữa hoặc cuối của giai đoạn Forming, nên thực hiện việc phân công phân nhiệm đối với các thành viên trong nhóm (mặc dù thành viên trong nhóm có thể bị thay đổi trong những giai đoạn sau đó). Bên cạnh đó giảng viên cũng nên lưu ý trong việc cân bằng giới tính trong mỗi nhóm, tránh xuất hiện tình trạng mất cân bằng giới tính gây ra một số bất cập như đã nói ở phần trên.

- Giảng viên cũng có thể nhờ sự hỗ trợ của Trưởng nhóm để thực hiện một số chiến thuật Pull. Bảng 2 cung cấp một số các câu hỏi trả lời theo kiểu Yes/No, đây là một danh 
sách câu hỏi nhằm kiểm tra những công việc cụ thể cần phải làm nhằm đảm bảo rằng các hoạt động nhóm được diễn ra thường xuyên và hiệu quả. Bảng câu hỏi này được trả lời và cung cấp lại cho Giảng viên hàng tuần và nó cũng được sử dụng trong suốt các giai đoạn còn lại của mô hình FSNPA.

Bảng 2. Bảng câu hỏi dành cho trưởng nhóm hàng tuần

\begin{tabular}{|c|c|c|}
\hline Câu hỏi & Nội dung & Yes/No \\
\hline 1 & Tôi đã chuẩn bị kế hoạch phân công công việc cho các thành viên trong nhóm ở tuần này. & \\
\hline 2 & $\begin{array}{l}\text { Tất cả / hầu hết các thành viên đều đồng ý rằng sự phân công phân nhiệm trong nhóm } \\
\text { là công bằng. }\end{array}$ & \\
\hline 3 & Tôi đã đề trình kế hoạch phân công công việc tuần này lên cố vấn học tập của nhóm tôi. & \\
\hline 4 & Kế hoạch đồ án của nhóm đã được điều chỉnh lại bởi ý kiến của cả nhóm trong tuần này. & \\
\hline 5 & $\begin{array}{l}\text { Bỏ qua câu này nếu chọn No ở câu } 4 \\
\text { Tất cả / hầu hết các thành viên trong nhóm đều đồng ý với những thay đổi trong kế } \\
\text { hoạch đồ án. }\end{array}$ & \\
\hline 6 & Không có xung đột trong nội bộ nhóm ở tuần này. & \\
\hline 7 & $\begin{array}{l}\text { Bỏ qua câu này nếu chọn Yes ở câu } 6 \\
\text { Tôi đã phân loại các xung đột trong nội bộ nhóm ở tuần này. }\end{array}$ & \\
\hline 8 & Tôi đã trò chuyện với các thành viên ít hoạt động / thụ động nhất trong nhóm ở tuần này. & \\
\hline 9 & Tôi đã ghi chú lại tất cả các điểm tốt và không tốt của nhóm đã diễn ra trong tuần này. & \\
\hline 10 & $\begin{array}{l}\text { Các thành viên trong nhóm của tôi cũng tự ghi chú lại các hoạt động tốt và không tốt } \\
\text { của họ trong quá trình thực hiện các nhiệm vụ của mình trong nhóm ở tuần này. }\end{array}$ & \\
\hline
\end{tabular}

Chú $y^{\prime}$ : Mỗi câu trả lời chọn Yes trong số 10 câu hỏi trên được tính tương ứng là 1 điểm. Nếu số điểm tổng hợp từ bảng trả lời là dưới 5 thì có thể kết luận cách tiếp cận và quản lý nhóm của Trưởng nhóm hiện tại là có vấn đề.

\subsection{Nhóm chiến thuật balance}

Chuyển sang giai đoạn Storming (giai đoạn bão tố), trọng tâm sẽ được đặt vào việc cải thiện giao tiếp trong nhóm, tăng cường việc học tập cá nhân và tạo điều kiện và đem lại cơ hội bình đẳng cho các thành viên trong nhóm thể hiện mình và ý tưởng của họ. Trong giai đoạn này giảng viên hướng dẫn đóng vai trò là trọng tài trong các xung đột và đối đầu giữa các thành viên trong nhóm. Chúng ta sẽ bàn tới một số chiến thuật được áp dụng ở giai đoạn này như sau:

- Bước vào giai đoạn Storming, đồ án CDIO đã chính thức khởi động. Các giảng viên sẽ cần phải thường xuyên tổ chức các cuộc họp cộng động hoặc họp riêng từng nhóm CDIO để nghe các nhóm trình bày về kế hoạch đồ án, mục tiêu và tầm nhìn của từng nhóm đối với đồ án của họ. Điều quan trọng của việc này không phải là để giảng viên đưa ra các bình luận về việc liệu ý tưởng đề xuất là đúng hay sai, mà quan trọng là để phân tích các lợi ích và nhược điểm của mổi ý tưởng, sau đó dành quyền tự chủ trong việc lựa chọn ý tưởng cho mỗi nhóm [6].

- Với mỗi sinh viên, họ cần ghi chú lại quá trình học tập và duy trì tốt sự cân bằng giữa học tập nhóm và học tập cá nhân để đánh giá được quá trình trưởng thành và phát triển các kỹ năng của bản thân họ. Để thực hiện điều này, bảng 3 là danh sách các câu hỏi trả lời theo kiểu Yes/No sẽ được trao cho mỗi thành viên trong nhóm để tự đánh giá hàng tuần. 
Như vậy tương tự ở giai đoạn Forming, bảng câu hỏi này sẽ được sử dụng liên tục từ giai đoạn Storming cho đến khi kết thúc đồ án.

Bảng 3. Bảng câu hỏi dành cho thành viên nhóm hàng tuần

\begin{tabular}{|c|c|c|}
\hline Câu hỏi & Nội dung & Yes/No \\
\hline 1 & $\begin{array}{l}\text { Để có } 1 \text { giờ họp và làm việc nhóm ở tuần này, tôi đã dành từ } 1,5 \text { đến } 2 \text { giờ để học } \\
\text { tập cá nhân và chuẩn bị từ trước đó. } \\
\text { Ghi rõ lý do nến chọn No: }\end{array}$ & \\
\hline 2 & $\begin{array}{l}\text { Tôi đã ghi chú tất cả các điểm tốt và chưa tốt của nhóm tôi và các thành viên trong } \\
\text { nhóm diễn ra trong tuần này để làm tài liệu tham khảo cho những môn học khác. }\end{array}$ & \\
\hline 3 & $\begin{array}{l}\text { Tuần này, tôi chỉ thực hiện các nhiệm vụ đã được phân công trước đó mỗi khi lên } \\
\text { lớp họp nhóm hoặc thảo luận nhóm. } \\
\text { Nếu chọn No, hãy ghi rõ địa điểm và thời gian bạn thục hiện nhiệm vụ của } \\
\text { mình trong đồ án (Ở nhà, quán café....): }\end{array}$ & \\
\hline 4 & $\begin{array}{l}\text { Tuần này tôi không tham gia vào việc ra quyết định cho một số vấn đề trong nhóm. } \\
\text { Giải thích cụ thể nếu chọn Yes: }\end{array}$ & \\
\hline 5 & Các thành viên khác phát hiện ra một số lỗi trong công việc của tôi ở tuần này. & \\
\hline 6 & Tôi đã hỗ trợ một số thành viên thực hiện nhiệm vụ của họ trong tuần này. & \\
\hline 7 & $\begin{array}{l}\text { Tôi không tham gia đồ án này vì tôi đang tham gia một môn học khác. } \\
\text { Nếu chọn Yes, hãy cho biết bạn đang tham gia bao nhiều đồ án? }\end{array}$ & \\
\hline 8 & Do dành nhiều thời gian và công sức cho đồ án này, tôi đã bỏ qua các môn học khác. & \\
\hline 9 & $\begin{array}{l}\text { Tuần này, tôi đã xung đột với một vài thành viên khác trong nhóm do bất đồng } \\
\text { quan điểm trong việc thực hiện một số nhiệm vụ. } \\
\text { Giải thích cụ thể nếu chọn Yes: }\end{array}$ & \\
\hline 10 & $\begin{array}{l}\text { Cho đến cuối tuần này, giảng viên hướng dẫn vẫn không cho phép chúng tôi thực } \\
\text { hiện trước một số nhiệm vụ của tuần sau. }\end{array}$ & \\
\hline
\end{tabular}

Chú ý: Với bảng câu hỏi trên, câu trả lời Yes sẽ tương ứng với 1 điểm và No là 0 điểm. Nếu tổng điểm của các câu hỏi $1,2,5,6$ và 8 trừ điểm tổng điểm của các câu hỏi 3,4 , $7,9,10$ bằng 0 hoặc nhỏ hơn 0 thì có thể kết luận sinh viên không duy trì được sự cân bằng giữa học tập nhóm và học tập cá nhân, và như vậy có nghĩa rằng việc học nhóm không đem lại lợi ích cho việc học tập cá nhân của họ.

- Bằng cách theo dõi kết quả tổng hợp từ các bảng trả lời của các thành viên trong nhóm, giảng viên có thể nhanh chóng xác định được những nhóm nào đang có xung đột nội bộ để can thiệp và giúp giải quyết các vấn đề một cách kịp thời. Trong quá trình can thiệp đó, giảng viên không nên dành sự ưu ái hoặc thiên vị cho bất kỳ một bên nào của sự xung đột dù đó là một cá nhân hay một nhóm sinh viên. Thay vào đó, giảng viên nên giúp phân tích các vấn đề xung đột và khuyến khích các thành viên trong nhóm tìm ra phương hướng giải quyết thông qua các lý luận phù hợp và đúng đắn.

- Trong giai đoạn này, các buổi thuyết trình về kế hoạch đồ án, các nhiệm vụ cần phải thực hiện nên được tổ chức thường xuyên. Trong đó, giảng viên nên dành cơ hội nói và trình bày cho những sinh viên thụ động để họ được thể hiện ý tưởng của mình; khuyến khích họ ngay khi họ có những ý tưởng hay và không nhất thiết răng ý tưởng đó phải mang tính khả thi. Bên cạnh đó, việc thuyết trình của mỗi nhóm cũng có thể giúp các nhóm khác tìm thấy được hướng tiếp cận vấn đề mới mẻ mà họ nên học tập hoặc phát hiện ra những thiếu sót của nhóm bạn và góp ý hoàn thiền những thiếu sót đó cho nhóm bạn, từ đó tăng cường thêm sự giao tiếp và đoàn kết trong lớp học. 
- Ngoài những vấn đề mà các thành viên nhóm thảo luận tổng kết để báo cáo thì giảng viên phải đặt thêm những câu hỏi bổ sung để phát huy tính tích cực hoạt động của nhóm. Giảng viên nên nhắc lại các ý kiến mà nhóm đã trình bày một lần nữa khẳng định lại ý kiến của nhóm để nhóm cần bổ sung ý kiến hay không. Nhấn mạnh các khái niệm, các ý quan trọng của bài học. Cuối những buổi thảo luận, giảng viên cần tóm tắt, tổng hợp, liên kết các ý kiến của từng nhóm thảo luận theo thứ tự để nêu bật được nội dung bài học.

Một vấn đề lớp cũng thường gặp ở giai đoạn Storming là nó có thể sẽ kết thúc sớm ở một số nhóm, tuy nhiên ở một số nhóm khác nó lại diễn ra chậm chạp, diễn tiến trong một thời gian dài và tán phá phần lớn những nỗ lực của các thành viên trong việc giữ gìn các mối quan hệ và kết quả làm việc chung của cả nhóm. Điều này sẽ có thể dẫn đến các xung đột xuất hiện ngày một nhiều hơn. Nếu trường hợp này xảy ra, giảng viên nên kịp thời có tác động trong việc thay đổi thành viên trong nhóm hoặc thay đổi cấu trúc nhóm để cải thiện tình hình.

\subsection{Nhóm chiến thuật push}

Nhóm chiến thuật này áp dụng cho những giai đoạn còn lại của quá trình phát triển của nhóm. Ở những giai đoạn này, vai trò của sinh viên trong hoạt động nhóm sẽ được đẩy lên ở mức cao nhất. Giảng viên lúc này chỉ cần thực hiện một số chiến thuật nhằm để thúc đẩy các thành viên trong nhóm tích cực hoạt động, nỗ lực hướng tới mục tiêu của họ.

- Ở những giai đoạn kề cuối này giảng viên thường tăng cường khối lượng công việc và giảm thời hạn thực hiện để tạo áp lực thúc đẩy các nhóm hoàn thành đồ án của họ. Tuy nhiên theo kinh nghiệm của chúng tôi việc này có thể ảnh hưởng đến khả năng và hiệu xuất làm việc của sinh viên không chỉ ở đồ án hiện tại mà còn ảnh hưởng đến các môn học khác sau này. Chúng tôi khuyến khích giảng viên hướng dẫn sinh viên cách theo dõi và kiểm tra tiến độ, rút ngắn ngày kết thúc nhiệm vụ hoặc đồ án sớm hơn nếu cảm thấy họ làm tốt. Bằng cách đẩy họ đến giới hạn một cách phù hợp mà không quá mang tính thúc ép, chúng ta có thể kiểm tra được năng lực và khả năng của sinh viên bên cạnh việc giúp họ trao đồi thêm kỹ năng quản lý tiến độ đồ án. Bên cạnh đó giảng viên cũng nên kéo dài ngày kết thúc đồ án nếu cảm thấy nhóm nào đó không thể đảm bảo kịp tiến độ kết hợp với việc hỗ trợ sinh viên giải quyết một số khó khăn trong quá trình thực hiện đồ án của họ.

- Thông thường một lớp CDIO có số lượng sinh viên ít (nhỏ hơn 15) thì do một giảng viên phụ trách, tuy nhiên ngoài những lúc lên lớp có thể sinh viên sẽ cần tới sự trợ giúp của giảng viên khi họ làm việc tại nhà, trong khi đó giảng viên lại đang bận ở lớp học khác. Lúc này việc cung cấp một danh sách các cố vấn học tập có cùng chuyên môn với giảng viên cho sinh viên có thể giúp chủ động liên hệ với bất kỳ người nào đang rỗi để được hỗ trợ. Điều này giúp sinh viên tự chủ hơn trong việc học.

- Ngay cả trong giai đoạn Forming hay Storming, những thành viên nhàn rỗi hoặc thụ động vẫn luôn là vấn đề tồn tại của mỗi nhóm. Do đó, giảng viên bằng cách kênh thông tin thu thập được phải xác định được các thành viên này trong lớp và trong từng nhóm và sau đó yêu cầu họ báo cáo tiến độ công việc của họ ngay tại lớp học để thúc đẩy các thành viên này 
cũng làm việc với nhóm. Nếu điều này không làm cho những thành viên thụ động trở nên năng động hơn thì ít nhất nó cũng sẽ làm thay đổi thái độ của những thành viên nhàn rỗi.

\section{Phản hồi của sinh viên đối với những thay đổi trong học tập nhóm khi áp dụng nhóm giải pháp P-B-P}

Nhóm giải pháp P-B-P đã được chúng tôi áp dụng và triển khai ở bốn lớp học bao gồm Công nghệ phần mềm, Hệ thống thông tin, Xây dựng và Điện tử viễn thông trong học kỳ cuối. Trong khi những giải pháp này đang dần được áp dụng rộng rãi và được đánh giá cao bỏi các giảng viên thuộc các chuyên ngành Điện tử viễn thông thì các khoa khác như Công nghệ thông tin, Xây dựng vẫn còn thận trọng trong việc nhân rộng giải pháp này trong các lớp học của họ, một phần vì họ có cấu trúc lớp học $\mathrm{CDIO}$ đã được thiết kế từ rất lâu và các thiết kế này cũng đang áp dụng một loạt các phương pháp tham khảo từ chương trình của Đại học Carnegie Mellon theo chương trình tiên tiến. Vì vậy, trong nỗ lực nhằm khẳng định giá trị thực tiễn của mô hình này, bên cạnh những đánh giá chủ quan, chúng tôi đã thực hiện một loạt các cuộc thảo luận nhóm tập trung ở 50 sinh viên trong số 200 sinh viên trong bốn lớp CDIO mà chúng tôi đã áp dụng nhóm giải pháp P-B-P này để tìm cho mình câu trả lời khách quan nhất. Nội dung các cuộc thảo luận tập trung vào những ý lớn được liệt kê ở bảng 4 . Thực tế, hầu hết các sinh viên đều không nhận ra việc chúng tôi triển khai nhóm giải pháp P-B-P vào các đồ án CDIO của họ ở học kỳ cuối. Kết quả là chúng tôi đã dành thời gian để giải thích qua một lượt ý tưởng của nhóm giải pháp P-B-P cho các sinh viên của mình. Sau đó hỏi họ xem thử họ có nhận thấy bất kỳ sự thay đổi hay cải tiến nào trong các đồ án CDIO ở học kỳ này so với học kỳ trước đó.

Bảng 4. Bảng chủ đề thảo luận điều tra tính hiệu quả của nhóm giải pháp P-B-P

\begin{tabular}{|l|l|}
\hline \multicolumn{1}{|c|}{ Chủ đề } & \multicolumn{1}{c|}{ Nội dung } \\
\hline 1 & $\begin{array}{l}\text { Thảo luận về 2-3 cải tiến (nếu có) mà bạn nhận thấy từ việc áp dụng nhóm giải pháp P-B-P } \\
\text { vào trong tồ chức lớp học và đồ án mà bạn đã tham gia. }\end{array}$ \\
\hline 2 & $\begin{array}{l}\text { Thảo luận về 2-3 cải tiến (nếu có) mà bạn nhận thấy về sự hỗ trợ của giảng viên trong quá } \\
\text { trình áp dụng nhóm giải pháp P-B-P. }\end{array}$ \\
\hline 3 & Thảo luận về 2-3 cái tiến (nếu có) về sự giao tiếp trong nhóm khi áp dụng nhóm giải pháp P-B-P. \\
\hline 4 & $\begin{array}{l}\text { Thảo luận về những thay đổi tích cực trong học tập của cá nhân bạn nhờ tham gia vào quá } \\
\text { trình học nhóm được áp dụng nhóm giải pháp P-B-P. }\end{array}$ \\
\hline 5 & $\begin{array}{l}\text { Xác định 2-3 thiếu sót lớn khi áp dụng nhóm giải pháp P-B-P vào quá trình học tập nhóm và } \\
\text { học tập cá nhân của bạn. }\end{array}$ \\
\hline
\end{tabular}

Kết quả phản hồi từ những cuộc thảo luận trả về có hơn $\mathbf{8 8 \%}$ số sinh viên cho rằng họ thấy thích thú đối với cách tổ chức lớp học và những cải thiện tích cực trong việc tương tác, giao tiếp giữa các thành viên trong nhóm (dựa trên những chỉ dẫn của giảng viên) và các trò chơi hoạt động trong lớp học cũng nhiều hơn và mang tính tương tác cao hơn. Có $\mathbf{6 2 \%}$ sinh viên tham gia thảo luận cho rằng sự chỉ dẫn của giảng viên đã cải thiện đáng kể, nó giúp các các nhóm giải quyết các mâu thuẫn xung đột trọng nội bộ một cách nhanh chóng và dễ dàng hơn. Đối với việc giao tiếp giữa các thành viên trong nhóm, sinh viên cũng đồng ý rằng họ cảm thấy được tôn trọng hơn bởi các thành viên khác trong nhóm,các vấn đề trong nhóm luôn được giải quyết bằng lý luận khách quan hơn là bằng cảm giác chủ quan (đây là điểm cải thiện hết sức quan trọng trong tương tác nhóm), từ đó họ cảm thấy gắn kết hơn với tập thể. Đối với học tập cá nhân và học tập nhóm, đa số sinh viên cho rằng họ đã cải thiện được việc học tập cá 
nhân, chiếm lĩnh được nhiều kiến thức hơn thông qua học tập nhóm trong và thậm chí là ngoài những giờ lên lớp, có tới $\mathbf{9 2 \%}$ sinh viên trả lời rằng họ sẵn sàng giúp đỡ các thành viên khác không chỉ là các vấn đề liên quan đến đồ án họ đang tham gia mà cả những vấn đề khác trong học tập. Về những thiếu xót của P-B-P, đa phần sinh viên đều cho rằng họ phải tiêu tốn thêm nhiều thời gian cho việc thực hiện các bảng trả lời câu hỏi hàng tuần, số lượng báo cáo và các cuộc họp nhóm cũng phải tăng lên mới có thể đảm bảo được sự thành công của đồ án.

Các nghiên cứu và cải thiện trong thời gian tới của chúng tôi tập trung nhiều vào việc làm rõ hơn giá trị của nhóm giải pháp P-B-P và khả năng phát triển và áp dụng P-B-P một cách bền vững và ngày càng tương thích nhiều hơn với các môn học ở chuyên ngành thuộc kỹ thuật. Dĩ nhiên để thực hiện được điều này, chúng tôi cần có những con số đánh giá bằng phương pháp thống kê, phục vụ cho mục đích này, chúng tôi đã chuẩn bị một danh sách các câu hỏi để thu thập nhiều hơn các thông tin cần thiết theo bảng 5 . Kết quả của cuộc khảo sát này sẽ là căn cứ để chúng tôi tiếp tục cải thiện giải pháp của mình và sẽ được tiếp tục trình bày trong một bài báo khác.

\begin{tabular}{|c|c|c|c|}
\hline \multicolumn{3}{|r|}{ Họ và tên sinh viên: } & Mã sinh viên: \\
\hline \multicolumn{4}{|c|}{ Chuyên ngành: } \\
\hline Câu hỏi & $\begin{array}{l}\text { Tùy } \\
\text { chọn }\end{array}$ & Nội dung & $\begin{array}{c}\text { Đáp án } \\
\text { (đánh X) }\end{array}$ \\
\hline \multirow{3}{*}{1} & \multicolumn{3}{|c|}{$\begin{array}{l}\text { Bạn có nhận thấy sự thay đổi hoặc cải thiện nào trong các đồ án CDIO trong học kỳ này? (Chi } \\
\text { chọn } 1 \text { đáp án) }\end{array}$} \\
\hline & A & Có. & \\
\hline & $\mathrm{B}$ & Không. & \\
\hline & $\mathrm{C}$ & Có một vài sự thay đổi. & \\
\hline & \multicolumn{3}{|c|}{ Liệt kê những thay đổi mà bạn thấy được: } \\
\hline \multirow{5}{*}{2} & \multicolumn{3}{|c|}{$\begin{array}{l}\text { Bạn cảm thấy hài lòng với vấn đề nào nhất với những điều chỉnh và cách bố trí lớp học mới trong } \\
\text { đồ án CDIO lần này? (Có thể chọn nhiều đáp án) }\end{array}$} \\
\hline & A & Có nhiều tương tác (trao đổi qua lại) giữa các thành viên trong nhóm. & \\
\hline & B & Có nhiều các hoạt động và trò chơi nhóm. & \\
\hline & $\mathrm{C}$ & Giảng viên dành nhiều sự hỗ trợ hơn cho các công việc của nhóm. & \\
\hline & \multicolumn{3}{|c|}{ Liệt kê những điều mà bạn thấy hài lòng: } \\
\hline \multirow{5}{*}{3} & \multicolumn{3}{|c|}{$\begin{array}{l}\text { Bạn cảm thấy KHÔNG hài lòng với vấn đề nào nhất với những điều chỉnh và cách bố trí lớp học } \\
\text { mới trong đồ án CDIO lần này? (Có thể chọn nhiều đáp án) }\end{array}$} \\
\hline & A & $\begin{array}{l}\text { Một số thành viên không ghi chép đầy đủ thông tin công việc của mình để } \\
\text { hổ trợ cho các thành viên khác. }\end{array}$ & \\
\hline & B & $\begin{array}{l}\text { Tôi không thể quản lý tốt lịch làm việc của mình bởi vì có nhiều yêu cầu } \\
\text { khác trong cùng một lúc. }\end{array}$ & \\
\hline & $\mathrm{C}$ & $\begin{array}{l}\text { Một số thành viên không thật sự cởi mở trong việc giải quyết các mâu } \\
\text { thuẩn trong các hoạt động thực hành. }\end{array}$ & \\
\hline & \multicolumn{3}{|c|}{ Liệt kê những điều mà bạn thấy hài lòng: } \\
\hline \multirow[b]{4}{*}{4} & \multicolumn{3}{|c|}{ Giảng viên/Cố vấn hỗ trợ công việc cho nhóm của bạn như thế nào? (Chọn 1 đáp án) } \\
\hline & A & $\begin{array}{l}\text { Giảng viên đã chủ động trong việc giúp đỡ nhóm mà không nhất thiết phải } \\
\text { được sinh viên yêu cầu? }\end{array}$ & \\
\hline & $\mathrm{B}$ & Giảng viên chỉ giúp đỡ khi sinh viên có câu hỏi. & \\
\hline & $\mathrm{C}$ & Giảng viên dường như đoán trước được những vấn đề mà nhóm sẽ gặp & \\
\hline
\end{tabular}




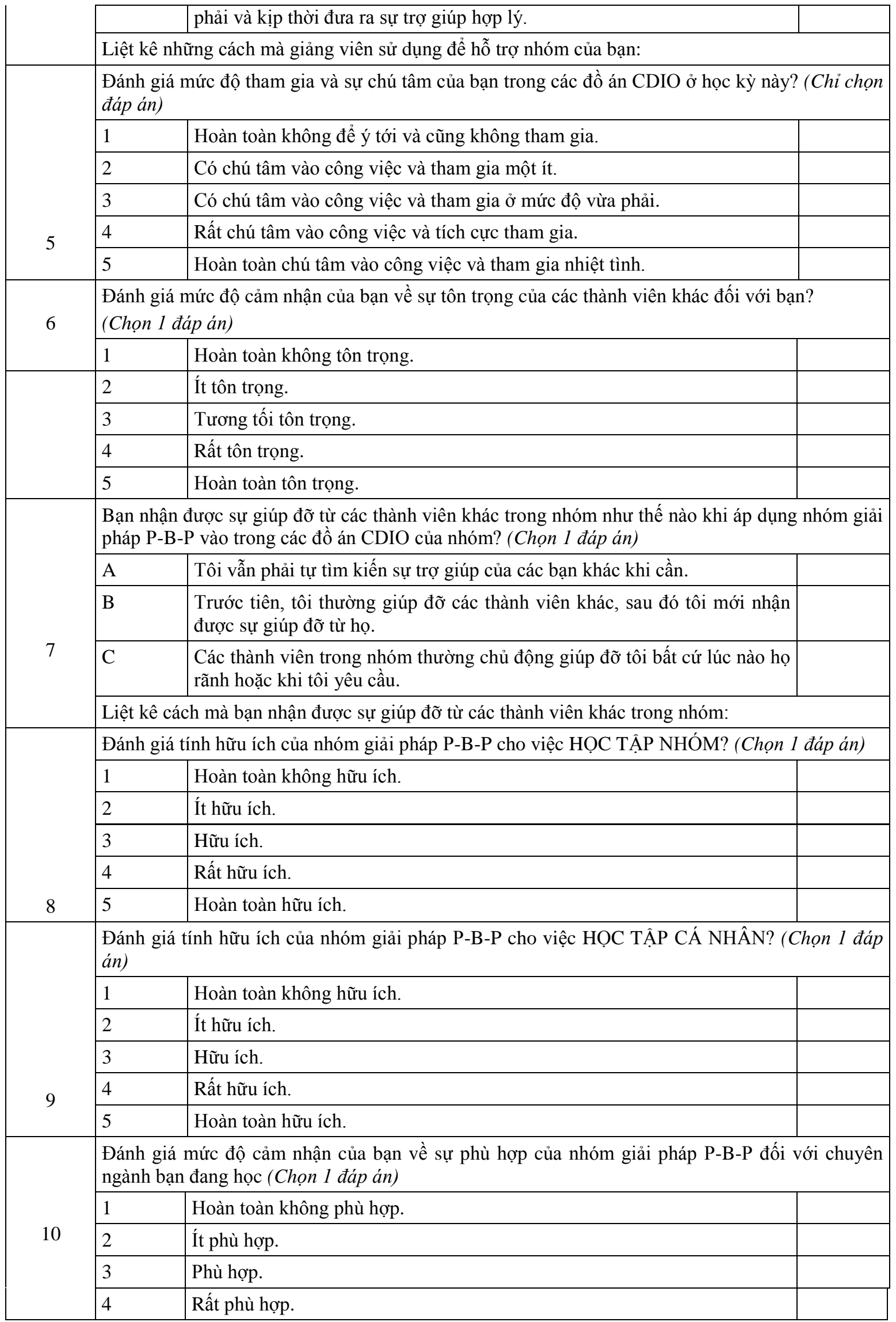




\begin{tabular}{|l|l|l|l|}
\hline & 5 & Hoàn toàn phù hợp. & \\
\hline
\end{tabular}

\begin{tabular}{|c|c|c|c|}
\hline & \multicolumn{3}{|c|}{$\begin{array}{l}\text { Chiến thuật nào trong nhóm giải pháp P-B-P đem lại hiệu quả nhất cho đồ án CDIO của bạn? } \\
\text { (Chọn } 1 \text { đáp án) }\end{array}$} \\
\hline & A & Chiến thuật PULL & \\
\hline & B & Chiến thuật BALANCE & \\
\hline \multirow{2}{*}{11} & $\mathrm{C}$ & Chiến thuật PUSH & \\
\hline & \multicolumn{3}{|c|}{ Giải thích lý do cho sự lựa chọn phía trên: } \\
\hline \multirow{7}{*}{12} & \multicolumn{3}{|c|}{$\begin{array}{l}\text { Trạng thái nào của mô hình FSNPA giúp bạn học được nhiều kiến thức và kỹ năng nhất trong đồ } \\
\text { án CDIO của bạn? (Chọn } 1 \text { đáp án) }\end{array}$} \\
\hline & A & FORMING & \\
\hline & B & STORMING & \\
\hline & $\mathrm{C}$ & NORMING & \\
\hline & $\mathrm{D}$ & PERFORMING & \\
\hline & $\mathrm{E}$ & ADJOURNING & \\
\hline & \multicolumn{3}{|c|}{ Giải thích lý do cho sự lựa chọn phía trên: } \\
\hline \multirow{5}{*}{13} & \multicolumn{3}{|c|}{$\begin{array}{l}\text { Ai là người chủ chốt trong việc giải quyết các xung đột trong đồ án CDIO của bạn? (Chọn } 1 \text { đáp } \\
\text { án) }\end{array}$} \\
\hline & A & Tất cả thành viên trong nhóm. & \\
\hline & B & Trưởng nhóm. & \\
\hline & $\mathrm{C}$ & Giảng viên/Cố vấn. & \\
\hline & \multicolumn{3}{|c|}{ Tùy chọn khác: } \\
\hline 14 & \multicolumn{3}{|c|}{ Liệt kê những thiếu sót của nhóm giải pháp P-B-P mà bạn nhận thấy được: } \\
\hline
\end{tabular}

\section{Kết luận}

Những vấn đề phát sinh trong học tập nhóm của sinh viên nói chung và sinh viên ngành kỹ thuật nói riêng trong các đồ án thường xuất hiện khá phổ biến trong các trường Đại học và các tổ chức giáo dục đang áp dụng mô hình CDIO. Các vấn đề về giao tiếp luôn đứng đầu bảng danh sách, bên cạnh đó các vấn đề về đảm bảo chất lượng học tập cá nhân bên cạnh học tập nhóm cũng làm cho tình hình triển khai CDIO gặp không ít khó khăn. Tuy nhiên chúng ta không thể sửa chữa những khiếm khuyết cho từng vấn đề một cách riêng lẽ vì mối tương quan của chúng. Bằng cách tập trung vào sự thay đổi và chuyển giao của những vấn đề này ở từng giai đoạn phát triển khác nhau của nhóm theo mô hình FSNPA, nhóm giải pháp P-B-P của chúng tôi cung cấp một cách tiếp cận chung để cải thiện chất lượng học tập cá nhân và nhóm theo một phương cách có chủ đích và có sự theo dõi và giám sát chặt chẽ của giảng viên.

Mặc dù vẫn còn nhiều nội dung cần phải thêm bớt hoặc thay đổi nhưng ở giai đoạn đầu áp dụng thử nghiệm các phương pháp cải tiến tại một số lớp học, nhóm giải pháp P-B-P đã đem lại một số kết quả khả quan đáng khích lệ. Có được những kết quả này là sự nỗ lực rất lớn của những người điều hành chương trình giáo dục của chúng tối và phối hợp với sự 
cống hiến rất nhiệt tình của hầu hết các giảng viên và sinh viên. Đây là tiền đề để chúng tôi hướng tới xây dựng một môi trường học tập thân thiện và có chất lượng cao đáp ứng được các yêu cầu của CDIO.

\section{Tài liệu tham khảo}

[1] Decuyper, S., Dochy, F., and Van Den Bossche, P. (2010). Grasping the Dynamic Complexity of Team Learning: An Integrative Model for Effective Team Learning in Organizations. U.S.: Educational Research Review, 5(2), pp. 111-133.

[2] Hmelo-Silver, C. E. (2004). Problem-based Learning: What and How do Students Learn? U.S.: Educational Psychology Review, 16: pp. 235-266.

[3] Kritzerow, P. (1990). Active Learning in the Classroom: The Use of Group Role Plays. U.S.: Teaching Sociology, 18 (2), pp. 223-225.

[4] NTL Institute (1954). The Learning Pyramid. Bethel, Maine, U.S.: The National Training Laboratories.

[5] Michaelsen, Larry K., Knight, Arletta B., and Fink, L. Dee (2002). Team-Based Learning: A Transformative Use of Small Groups. New York, U.S.: Praeger.

[6] Osborn, A. F. (1963). Applied Imagination: Principles and Procedures of Creative Problem Solving ( $3^{\text {rd }}$ Edition). New York, NY, U.S.: Charles Scribner's Son.

[7] Tuckman, Bruce (1965). Developmental Sequence in Small Groups. U.S.: Psychological Bulletin 63 6), pp. 384-399. 